Ageing E Society 39, 2019, 381-408. (C) Cambridge University Press 2017.

This is an Open Access article, distributed under the terms of the Creative Commons Attribution licence (http://creativecommons.org/licenses/by/4.o/), which permits unrestricted re-use, distribution, and reproduction in any medium, provided the original work is properly cited.

doi:10.1017/So1 44686X1700o964

\title{
The dynamics of social care and employment in mid-life
}

\author{
MADELIN GOMEZ-LEON*†, MARIA EVANDROU*†, \\ JANE FALKINGHAM $\dagger$ and ATHINA VLACHANTONI*†
}

\begin{abstract}
This study investigates the relationship between the provision of informal care to older parents/parents-in-law and the employment status of adult children in midlife. The study analyses unique panel data for a cohort of individuals born in $195^{8}$ in Britain, focusing on respondents at risk of providing care (i.e. with at least one

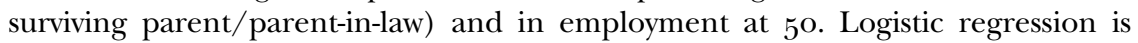
used to investigate the impact of caring at $5^{\mathrm{O}}$ and 55 on employment status at 55 , controlling for socio-demographic characteristics, the respondent's health status and their partner's employment status. Separate models examine (a) the likelihood of exiting the labour force versus continuing work, and (b) amongst those continuing in work, the likelihood of reducing hours of employment. Different types of care (personal, basic and instrumental support) are distinguished, along with hours of caring. The results highlight that providing care for more personal tasks, and for a higher number of hours, are associated with exiting employment for both men and women carers. In contrast, the negative impact of more intense care-giving on reducing working hours was significant only for men - suggesting that women may juggle intensive care commitments alongside work or leave work altogether. Facilitating women and men to combine paid work and parental care in mid-life will be increasingly important in the context of rising longevity.
\end{abstract}

KEY WORDS - informal care, parental care, labour force participation, National Child Development Study, cohort study.

\section{Introduction}

With rising longevity, the onset of, and deterioration in, limitations in activities of daily living is shifting towards older ages, particularly beyond the age of 75, with implications for the need for social care (Agree and Glaser 2009;

* ESRC Centre for Population Change, University of Southampton, UK.

$\dagger$ Centre for Research on Ageing, University of Southampton, UK. 
Christensen et al. 2009; Loken, Lundberg and Riise 2014; Vlachantoni et al. 2015; Wittenberg et al. 2006). Previous research has highlighted the central role of the family in the provision of informal care, particularly from one's spouse or adult children (Glaser, Evandrou and Tomassini 2006; Litwin and Stoeckel 2013). In countries with diverse family arrangements and policies on the provision of social care such as England, Spain and the United States of America (USA), research has indicated that it is primarily the adult children who provide informal care to their older parents (Sole-Auro and Crimmins 2014). The prevalence of such care-giving peaks in mid-life, between ages $45^{-64}$ (Robards et al. 2015).

Increasing care-giving responsibilities during mid-life may affect adult child carers' participation in the labour market, as there is a time constraint on the ability to take up multiple roles (King and Pickard 2013; Loken, Lundberg and Riise 2014; Michaud, Heitmueller and Nazarov 2010; Plaisier, Broese van Groenou and Keuzenkamp 2015; Proulx and Le Bourdais 2014; Stewart 2013). Previous research in the United Kingdom (UK) has found that economically active individuals are less likely to provide care compared to inactive individuals (Vlachantoni 2010); and when informal carers are in paid work, they earn significantly less (Carmichael and Charles 2003; Evandrou, Glaser and Henz 2002; Proulx and Le Bourdais 2014). Van Houtven, Coe and Skira (2013), using US data, found that women care providers who continued working decreased their employment by three to ten hours per week. However, the same study found that there was little effect of care-giving on working men's hours or wages, a finding further supported by Leigh (2010) using panel data for Australia. Thus, the relationship between care provision and employment remains both gendered and contested.

Much of the work on this topic has used cross-sectional data-sets, with individuals' employment status and caring roles observed at only one point in time (Ciani 2012; Farkas and Himes 1997; Michaud, Heitmueller and Nazarov 2010; Trukeschitz et al. 2013; Vlachantoni 2010). Recent studies using longitudinal data-sets allow the identification of changes in caregiving and employment status over time, informing the relationship between these roles within a lifecourse framework. Most of these recent studies emanate from the North American context (Lee and Tang 2015; Lumsdaine and Vermeer 2015; Proulx and Le Bourdais 2014; Skira 2015) with fewer studies from the UK (Carr et al. 2016; King and Pickard 2013).

The aim of this paper is to investigate the effect of adult children caring for their parents/parents-in-law on the probability of children changing their status in employment, differentiating between reducing their working hours and stopping work altogether. The paper addresses the following two questions: 
- Are employed individuals more likely to cease employment if they take on caring responsibilities, provide specific types of help or intensify their support to their parents/parents-in-law during mid-life?

- Among those mid-life adult children who continue to work, are their working hours affected by the type or intensification of their caring role?

Past research has found mixed results when analysing the impact of care provision on the employment status of the care-giver, taking into account the co-residential nature of support, caring trajectories and the intensity of care provided at one point in time. In this paper, we extend previous studies by analysing the impact not only of the trajectories of the caregiving role for both men and women, but also differentiate between the type of caring tasks provided as well as examining the change in the intensity of the care provided over time.

\section{Relationship between informal parental care and employment}

Individuals' involvement in multiple roles over the lifecourse, such as family roles (caring for older parents or dependent children) and paid employment may affect the balance of time, involvement and satisfaction relating to each role. Existing research has evidenced that a growing number of mid-life individuals, especially women, are faced with 'juggling' multiple roles (Berecki-Gisolf et al. 2008; Carmichael and Charles 2003; Evandrou, Glaser and Henz 2002). These roles may be positively or negatively combined according to 'the extent to which an individual is equally engaged in - and equally satisfied with - his or her work role and family role' (Greenhaus, Collins and Shaw 2003: 513).

In order to explain the impact of multiple roles within a work-life balance framework, two contrasting perspectives of role theory have been used role strain and role enhancement. The role strain theory hypothesises that a conflict emerges when an individual is involved in multiple roles. This implies that the demands and level of stress rise when a new responsibility starts or intensifies, and as a consequence time dedicated to existing roles is negatively affected (Goode 1960). Thus, under this perspective, we can expect a negative association between caring and employment. The commencement of a new caring role, or the intensification/continuation of an existing caring role, could lead individuals to reduce their working hours or to switch to a part-time job, as Carmichael et al. (2008) found in their research based on in-depth interviews with informal caregivers in the UK. In contrast, the enhancement hypothesis asserts that being involved in multiple roles may positively affect individuals' lives (Marks 1977). For instance, combining a caring role whilst remaining in the labour market could reflect the availability of flexible work conditions, 
paid work may offer respite time from caring responsibilities and there may be positive financial benefits (Carmichael et al. 2008), although such benefits are more pronounced for men carers compared to women carers (Proulx and Le Bourdais 2014). This perspective supports a positive association between care-giving and employment participation. Thus, under this perspective we would expect the commencement of a new caring role or the continuation of an existing caring role (with the same, a lower or a higher number of hours) not to affect the care-giver's chances of being in employment or the number of their working hours.

In this paper, we examine whether the provision of informal support (either a new role or an existing role performed over time, and the different types of support included) and the time spent providing support to parents/ parents-in-law (increasing hours of support over time) are related to changes in the employment status of adult children. Moreover, the paper explores whether there are differences in the impact of the care-giving role on one's employment by the gender of the care-giver. Given the focus of the paper on care provision towards parents/parents-in-law, rather than children or other younger family members, we expect the role strain theory to be more relevant to the study of how carers' employment patterns are affected, as opposed to other aspects of carers' lives (e.g. feelings of reward, obligation, etc.). As such, we hypothesise that the provision of care affects the care-giver's employment when such provision intensifies or is concentrated in certain types of task (such as personal needs for daily day activities), thereby resulting in a negative impact on employment status. Drawing on existing literature (Berecki-Gisolf $e t$ al. 2008; Van Houtven, Coe and Skira 2013), we would also expect such negative effects to be stronger for women than for men, and for there to be evidence supporting the role enhancement theory for men carers only.

\section{Previous research findings}

Previous empirical studies have found mixed results with regard to the relationship between the provision of informal care and the carer's employment status. In general, most research has identified a negative relationship, with care associated with a reduction in working hours (Carmichael and Charles 2003), the cessation of paid work altogether (Carmichael, Charles and Hulme 2010) or a deterioration in the carer's financial wellbeing (Lee et al. 2014). However, after controlling for the carer's characteristics, some research has found evidence of a reduction in working hours (Lilly, Laporte and Coyte 2010), particularly among women and those with higher educational qualifications (Carmichael et al. 2008). Michaud, Heitmueller and Nazarov (2010) found a small 
negative effect of caring on the employment of carers who provide co-residential care, but no effect for carers providing care outside their household, while Berecki-Gisolf $e t$ al. (2008) found a negative effect on employment only for those individuals who were providing intense care.

Relatively few studies have used a longitudinal approach, in part reflecting the scarcity of available data. An Australian study explored the effect of care provision on employment using both cross-sectional and longitudinal methods, and found stronger negative effects in the former analysis compared to the latter (Leigh 2010). A recent study investigating the impact of providing care on the risk of leaving employment in Canada found an elevated risk of stopping work amongst women who were working full-time (3o hours or more per week), suggesting that less-demanding work (in terms of time and flexibility) may better facilitate individuals to combine paid work with informal caring for their parents (Proulx and Le Bourdais 2014). However, important confounders such as the intensity of caring and the health of the carer were not included. Of the limited prior studies in the UK context, Carmichael et al. (2008) analysed the employment status of a small sub-sample of carers in England prior to and after the start of care provision. They found that the start of care provision was associated with a reduction both in working hours and in the chances of being in employment altogether, with stronger effects for those providing more intense care ( $5^{\mathrm{o}}$ hours or more per week). Interestingly, among those caring, this study found no differences between men and women, or between different occupational categories. The importance of taking the intensity of care provision into account was also emphasised by King and Pickard (2013), who found that caring for ten hours or more per week was detrimental to women's attachment to the labour market. A similar finding was noted by Carr et al. (2016), with the provision of more than ten hours of care per week posing a greater risk to exiting work among women working full-time compared to women working part-time. Michaud, Heitmueller and Nazarov (2010), using data from six waves of the British Household Panel Study (2000-2005), examined the impact of the intensity and type of care provided at baseline on future employment, distinguishing between two types of care, extra-residential and co-residential care (i.e. people living either away from or with the person they care for). They found a small but statistically significant impact of co-residential care-giving on future employment but an insignificant effect for extra-residential care-giving. Thus, the literature suggests that both the type and the intensity of care, in terms of the number of hours provided, may matter. This body of literature has also highlighted the importance of the characteristics of employment and of factors relating to the carer and their family's needs (Grzywacz and Marks 2000). 
This paper aims to contribute to the existing literature in five distinct ways. Firstly, despite recent studies showing an increasing involvement by men in care provision, the majority of past research has focused on women's provision of care, given the gendered nature of this role. Our paper analyses the impact of caring on the employment status of both men and women. Secondly, we take a holistic approach to understanding the impact of caring. We begin by distinguishing between the type of caring tasks provided, including personal support and assistance with other tasks within and outside the household. We then analyse the impact of changing care-giving status over time on the carers' employment participation. Finally, we consider not only the onset of the caring role and the type of care provided, but also the intensification of the caring role between two points in time. Previous studies have found that starting to care for ten or more hours is associated with stopping one's work or reducing their hours (Carr et al. 2016; King and Pickard 2013), whereas some research has found no such association when taking into account the hours of care provided by either new or continuous carers (Leigh 2010). Investigating the effect of intensifying care provision (i.e. increasing the number of hours of care) on either stopping work or reducing working hours is another unique feature of our analysis. Thirdly, we include in the analysis non-co-residential provision of support, in contrast to much previous literature which has studied the provision of care within the household and found a negative impact on the carer's employment. A fourth element of our study is the focus on care provision towards older parents or parentsin-law (including provision of care outside the household), which is a particular strength of the study as it allows the investigation of the 'pure' impact of such care on adult children's employment status and patterns. In addition, the focus on care towards parents/parents-in-law only allows us to contribute to a better understanding of changing family structures and increasing 'role-juggling' in mid-life (Berecki-Gisolf et al. 2008). Finally, to our knowledge, this is the first time that the National Child Development Study (NCDS) has been used to analyse the provision of support towards relatives in Britain and its effect on both men and women carers' employment status.

\section{Methods}

\section{Data}

This research uses data from the NCDS, a cohort study of all children born in a single week in March $195^{8}$ in Britain that have been followed up through the course of their lives (University of London, Institute of 
Education and Centre for Longitudinal Studies 2012; 2015). For this study we use the information collected in Wave 8 (2008/og) and Wave 9 (2013/ 14 ), when the cohort were aged $5^{\circ}$ and 55 , respectively, which is when information regarding the provision of support to aged parents was first collected in the study. From a total sample of 9,137 individuals interviewed at age 55, the analysis here is restricted to individuals with full interviews at both age $5^{\mathrm{O}}$ and $55(\mathrm{~N}=8,362)$. The sample is then further restricted to cohort members who are 'at risk' of providing parental care, i.e. who have at least one living parent/parent-in-law at both ages $(\mathrm{N}=6,484)$. Given the paper's objective of analysing the impact of caring on changes in the carer's employment patterns (between ages $5^{\mathrm{O}}$ and 55 ), a further 813 individuals are excluded because they were not working at age $5^{\circ}$. Another $5^{\circ}$ individuals are excluded from the analysis due to missing information in the covariates for the models. The final analytical sample comprises 5,621 individuals who were in employment at age $5^{\circ}$ and who have at least one parent or parent-in-law alive at both ages $5^{\mathrm{O}}$ and 55 .

As is the case with most longitudinal studies, the NCDS is affected by attrition. The analysis of attrition and missing data in this data-set has found that attrition is higher among men respondents, among individuals with a lower socio-economic status and those with lower educational qualifications (Hawkes and Plewis 2006). Our sample may also be affected by differential mortality amongst the respondents' older parents. A priori, we might anticipate that mortality would be higher amongst those whose parents came from lower socio-economic groups and thus the focus on those at risk of caring, i.e. with at least one surviving parent or parent-in-law, may result in a sample further skewed towards those individuals with higher socioeconomic status. However, the picture is complicated by socio-economic differences according to the respondents' age of experiencing parenthood, as individuals from lower socio-economic groups are more likely to have older parents. As a result, the two effects could offset each other, making it difficult to ascertain whether having surviving older parents/parents-inlaw is associated with a lower or higher socio-economic status.

\section{Measures}

Main predictors. The main predictors in the study relate to the provision of care and its intensity, measured as the number of hours of care provided per week. Information relating to the type of care provided and its intensity was collected at both waves using the same question and a list of tasks/help provided to parents or parents-in-law.

Conditionally on having at least one relative alive (either parent or parent-in-law), respondents were asked about the provision of care to 
each of them: 'Do you regularly or frequently do any of the following things listed for your parents or parents-in-law?' Then, they were shown a card with the following items: Giving them lifts in your car if you have one/Shopping for them/Providing or cooking meals/Helping with basic personal needs like dressing, eating or bathing/Washing clothes, ironing or cleaning/ Dealing with personal affairs (e.g. paying bills, writing letters)/Decorating, gardening or house repairs/Financial help/Any other help/None of these.

For those who mentioned that they did provide at least one of the types of help to their relatives, the respondents were asked: 'How many hours do you spend doing this/these things for your parents or parents-in-law in a typical week?', with respondents entering the number of hours (including less than one hour as decimal points) ranging between o and 168 hours.

With the information on care provided at both age points, three measures of care-giving were constructed: (a) types of care-giving, (b) care-giving trajectories and (c) intensification of care-giving. The types of care-giving variable refers to the care provided at one point in time, whereas the other two variables refer to the change of care-giving status and the change in the intensity of the care provided over time.

The first care-related predictor is the types of care-giving provided. In order to construct this variable, we first created the variable Care with three categories, which combine the nine items of caring tasks distinguished in the survey, comprising what are commonly known as activities of daily living (ADLs) and instrumental activities of daily living (IADLs). The first of three categories includes support provided with three key ADLs: dressing, eating and bathing (referred to hereafter as 'personal support'). The second and third categories refer to support provided with IADLs, which we have separated in two groups in order to create a scale of support distinguishing between 'basic' activities that are required on a regular basis (e.g. cooking) and support with tasks which may be more irregular (e.g. gardening), termed 'instrumental support'. The categories of our Care variable are as follows:

1. Personal support: dressing, eating, bathing.

2. Basic support: washing clothes, ironing, cleaning, cooking.

3. Instrumental support: financial assistance, shopping, transportation, gardening, personal affairs, any other.

For the purposes of this analysis, we take into account that individuals could have been providing help with one or more of these categories simultaneously. Thus, using the variable Care at age 55 , we construct the variable types of care-giving, which will be used in the models, with the following categories: 
1. Did not provide care (not providing care at age 55).

2. Personal care combined (those who were providing help with personal care tasks only, or personal care combined with support for basic and/ or instrumental care tasks).

3. Basic care combined (those who were helping with basic care only, or basic and instrumental care).

4. Instrumental care only (those who were helping with instrumental care only).

Among those who are employed at age $5^{\circ}$ and who are 'at risk of caring', Table 1 shows the percentage who provided care at ages $5^{\mathrm{O}}$ and 55 , distinguishing the type of the care provided and the intensity. A number of key points stand out. Firstly, more than 6o per cent of both men and women are providing help to their older relatives, with a higher proportion of men than women providing care at both ages $(61$ versus 57 per cent at age $5^{\mathrm{o}}$, and 68 versus 64 per cent at age 55 , men and women, respectively). These findings contrast with previous research, where the gendered nature of care provision in mid-life was evident, with more women providing support. In our study, the use of a broader concept of informal support, comprising any task - including in the instrumental care category, suggests that men are providing a great deal of support with tasks that are not usually taken into account in most analyses, where usually the focus is on co-residential care or help with chores tasks. This is corroborated by Table 1, which shows that most of the care provided is in the instrumental care category, with the proportion of men providing instrumental support being 10 percentile points higher than for women.

Examining the types of care-giving shows an increase between ages $5^{\circ}$ and 55 in the percentage of individuals providing personal care combined with other types of care (doubling for both sexes) and an increase among those providing basic care combined with other types of care. However, there are small declines in the percentages of those providing instrumental care. This could be reflecting the fact that although the majority of individuals are providing low-intensity care and instrumental care to their parents/parents-inlaw, the dynamic process of the care itself, with increasing needs from their relatives, means that more carers are involved either for longer hours or in more intense types of care, such as personal or basic care. This is borne out by the data on hours of care. Although the majority of care provided at both ages $5^{\mathrm{O}}$ and 55 is of a low intensity (less than ten hours/week), nevertheless the percentage of children in mid-life providing intense caring (more than ten hours/week) increases over time, more than doubling for men between ages $5^{\mathrm{o}}$ and 55 ( 3 to 7 per cent) and almost doubling for women ( 7 to 11 per cent). 
TABLE 1. Individuals providing care and type of caring provided to parents or parents-in-law

\begin{tabular}{|c|c|c|c|c|}
\hline & \multicolumn{2}{|c|}{ Age $5^{\circ}$} & \multicolumn{2}{|c|}{ Age 55} \\
\hline & Men & Women & Men & Women \\
\hline & \multicolumn{4}{|c|}{ Percentages } \\
\hline Types of care-giving: & & & & \\
\hline Did not provide care & 39.0 & 42.9 & 32.2 & 35.8 \\
\hline $\begin{array}{l}\text { Personal }{ }^{1} \text { care (either alone or with } \\
\text { basic/instrumental) }\end{array}$ & 2.5 & $4 \cdot 6$ & $5 \cdot 4$ & 8.7 \\
\hline Basic $^{2}$ care (either alone or with instrumental) & 13.2 & 18.7 & 18.4 & 22.3 \\
\hline Instrumental $^{3}$ care only & $45 \cdot 3$ & $33 \cdot 7$ & 44.1 & 33.2 \\
\hline \multicolumn{5}{|l|}{ Intensity of care-giving: } \\
\hline Did not provide care & $39 \cdot 0$ & $4^{2.9}$ & 32.2 & 35.8 \\
\hline$<10$ hours & 57.8 & $5^{0.5}$ & 60.4 & $5^{2.8}$ \\
\hline$\geq 10$ hours & 3.2 & 6.6 & $7 \cdot 4$ & 11.4 \\
\hline Number of people at risk of providing care & 3,013 & 2,608 & 3,013 & 2,608 \\
\hline
\end{tabular}

Notes: 1. Support with dressing, eating, bathing. 2. Support with washing clothes, ironing, cleaning, cooking. 3. Support with financial assistance, shopping, transportation, gardening, personal affairs and others.

Source: Authors' analysis of the National Child Development Study Wave 8 (2008/og) and Wave $9(2013 / 14)$.

Looking at the care-giving role from a dynamic perspective, the care-giving trajectories variable is constructed here to account for repeated care-giving in two points in time, thus the variable captures changes in caring status as measured at ages $5^{\mathrm{O}}$ and 55 . We cannot ascertain whether the individual was providing care continuously between these ages. In this sense, we are assuming that the recurrence of caring at both time-points implies stability in, or a longer overall duration of, the caring role, and thus a potentially stronger impact on the employment status of the care-giver. We measured the care-giving trajectories with the following four categories:

1. Never cared (not providing care at any of the waves, either at age $5^{\mathrm{O}}$ or $55)$.

2. Stopped caring (those who were caring at age $5^{\circ}$ but were not caring at age 55 ).

3. Started caring (those who were not caring at age $5^{\mathrm{o}}$ but were caring at age 55 ).

4. Repeated caring (those who were caring at both ages $5^{0}$ and 55 ).

The third predictor was derived from the change in care-giving intensity between ages $5^{\mathrm{O}}$ and 55 . We consider as a sizeable change in caring hours an increase of more than five hours per week (we also explored an 
increase by any number of hours, or by ten hours or more, per week, however the five-hour threshold produced the most meaningful results). The variable on the intensification of caring between ages $5^{\circ}$ and 55 was constructed with the following four categories:

1. Never cared (not providing care at any of the waves, either at age $5^{\circ}$ or $55)$.

2. Stopped caring (those who were caring at age $5^{0}$ but were not caring at age 55 ).

3. New carers and carers with the same or reduced number of hours of care.

4. Increased hours (change of more than five hours/week in the provision of care between ages $5^{\circ}$ and 55 ).

Table 2 shows the changes in care-giving status and intensification of caring between ages $5^{\mathrm{O}}$ and 55 . Looking at the care-giving trajectories, we can observe that 32 per cent of men and 36 per cent of women were either not caring at both ages or had stopped caring between ages $5^{\mathrm{O}}$ and 55 . It is of note that the majority of the individuals were providing care at both ages (labelled here as 'repeated caring'), with almost half of the sample for both men and women in this category, while around 18 per cent had started caring at age 55. Previous research has used similar variables to describe the dynamics of care-giving roles, analysing the impact of a repeat or new caring role on the employment of the care-giver. In our study, we extend this analysis by including the change in the number of hours of care provided over time. The intensification of caring variable shows that around 8 per cent of the cohort increased their hours of caring per week (by more than five hours), and this trend was more prevalent among women compared to men (9 versus 7 per cent, respectively). Bearing in mind that a person needs to be caring at both ages $5^{\mathrm{O}}$ and 55 to be classified as having intensified their role, nearly one-fifth $(19 \%)$ of repeat women carers and over a sixth $(14 \%)$ of repeat men carers had extended their time commitment over the five-year period.

Employment status. The carer's employment status is recorded at both ages $5^{\mathrm{O}}$ and 55 with the following categories: full-time employment (3o hours or more a week), part-time employment (less than 30 hours a week) and not working. We also have the weekly working hours in each wave (including main and second jobs, and overtime hours). Table 3 shows that at age $5^{\circ}$, women were more likely than men to be working for fewer hours per week ( $<25$ hours/week), which is an important point before considering changes in such working patterns over time. 
T A B L E 2. Men and women in employment at age 50 and who were at risk of caring at ages 50 and 55, by changes in caring status and intensity

\begin{tabular}{lrrr}
\hline & Men & Women & Total \\
\hline Care-giving trajectories: & & Percentages & \\
$\quad$ Never cared & 21.0 & 25.1 & 22.9 \\
Stopped caring & 11.2 & 10.7 & 10.9 \\
Started caring & 18.0 & 17.9 & 17.9 \\
Repeated caring & 49.9 & 46.4 & 48.2 \\
$\quad$ Total & 100.0 & 100.0 & 100.0 \\
Intensification of caring: & & & \\
$\quad$ Never cared & 21.0 & 25.1 & 22.9 \\
Stopped caring & 11.2 & 10.7 & 10.9 \\
New carers and carers with same or reduced hours & 60.8 & 55.4 & 58.3 \\
Increased hours (change of $>5$ hours between & 7.0 & 8.8 & 7.9 \\
ages 50 and 55) & 100.0 & 100.0 & 100.0 \\
$\quad$ Total & 3,013 & 2,608 & 5,621 \\
Number of people at risk & & & \\
\hline
\end{tabular}

Source: Authors' analysis of the National Child Development Study Wave 8 (2008/og) and Wave $9(2013 / 14)$.

Taking into account both waves, Table 4 shows the change in employment status among those who were in employment at age $5^{\mathrm{o}}$. Nearly half of the cohort individuals have made some adjustments to their working pattern, with the majority reducing their working hours, with 44 and $4^{1}$ per cent, men and women, respectively, and overall 9 per cent of all respondents having stopped working altogether by age 55 (8\% for men and $10 \%$ for women).

We are interested in whether the changes in employment found in the overall sample are more pronounced for those who have other responsibilities (in this case caring for parents/parents-in-law) and whether there are characteristics of the caring role that significantly affect employment participation. Two outcome variables were constructed to investigate changes in

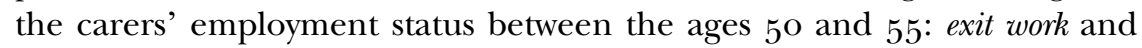
reduced work hours.

Exit work identifies whether the carer stopped working or not: continued working within the same category, or moved from part-time to full-time work or vice versa (o); and not working in the following wave (1).

Reduced work hours indicates a change in the weekly hours of work among those who were working at both waves (ages $5^{\circ}$ and 55 ). The variable combines information on employment status and hours of employment and contains two categories: working the same or more hours than in the previous wave, or having moved from part-time to full-time 
T A B LE 3. Men and women in employment at age 50 by working hours

\begin{tabular}{lccr}
\hline Weekly working hours & Men & Women & Total \\
\hline & & Percentages & \\
$<25$ & $3 \cdot 4$ & $24 \cdot 5$ & 13.2 \\
$25^{-34}$ & $4 \cdot 3$ & 20.7 & 11.9 \\
$35^{-39}$ & 18.8 & 24.2 & 21.3 \\
$4^{-}-49$ & 41.6 & 21.5 & 32.3 \\
$5^{0+}$ & 32.0 & $9 \cdot 1$ & 21.3 \\
Total & 100.0 & 100.0 & 100.0 \\
& & & \\
\hline
\end{tabular}

Source: Authors' analysis of the National Child Development Study Wave 8 (2008/og).

employment (from 29 hours or less, to more than 30 hours a week) (o); and reduced their working hours, or changed from full-time to part-time work (1).

Control variables. A range of socio-demographic characteristics of the adult children (recorded at baseline prior to any change in their employment) were included as covariates in order to account for observable heterogeneity: sex, marital status, living arrangements (e.g. with parents/parents-inlaw), health status, occupational social class, housing tenure, education, carers' working hours at age $5^{\mathrm{o}}$, and employment status for both the adult child and their partner. Other characteristics such as the respondents' income and whether they were living with dependent children were included in the preliminary models but were not significant, thus they were excluded from the final models and the descriptive tables.

\section{Data analysis}

The analysis investigates the association between care provision and employment. Descriptive bivariate analysis explores the relationship between changes in the carer's employment status between ages $5^{\circ}$ and 55 and the caring trajectory, the type of care provided and the intensification of care (Table 5). The impact of caring for one's parents/parents-in-law on the employment status of the adult children is then examined using logistic regression (Tables 6 and 7). The first set of models (Models 1-3) examine whether the risk of stopping work altogether is associated with the predictors (each predictor is examined in independent models), whereas the second set of models (Models $4^{-6}$ ) corresponds to analysing the risk of reducing working hours, conditional on being in employment at both age

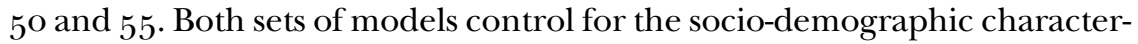
istics and the health status of the adult children. It is important to note that 
$\mathrm{T} \mathrm{A} \mathrm{B} \mathrm{L} \mathrm{E} 4$. Men and women in employment at age 50 and who were at risk of caring at ages 50 and 55, by changes in employment status

\begin{tabular}{|c|c|c|c|c|}
\hline $\begin{array}{l}\text { In employment at } \\
\text { age } 5^{\circ}\end{array}$ & $\begin{array}{l}\text { Did not reduce } \\
\text { hours }\end{array}$ & $\begin{array}{c}\text { Reduced working } \\
\text { hours }\end{array}$ & $\begin{array}{l}\text { Stopped } \\
\text { working }\end{array}$ & Total \\
\hline & \multicolumn{4}{|c|}{ Percentages $(N)$} \\
\hline Men & $4^{8.4}\left(1,45^{8}\right)$ & $43.9(1,322)$ & $7 \cdot 7(233)$ & $100.0(3,013)$ \\
\hline Women & $48.3(1,259)$ & $41.3(1,076)$ & $10.5(273)$ & $100.0(2,608)$ \\
\hline Total & $48.3(2,717)$ & $4^{2.7}(2,398)$ & $9.0(5 \mathrm{o6})$ & $100.0(5,621)$ \\
\hline
\end{tabular}

Source: Authors' analysis of the National Child Development Study Wave 8 (2008/og) and Wave $9(2013 / 14)$.

although the research design allows us to analyse the effect of being a carer on the employment changes of the cohort individuals at follow-up, given that we do not know the exact timing and order of the changes in work hours and in care-giving between ages $5^{\mathrm{O}}$ and 55 , we are unable to fully disentangle the causal effect of caring on employment.

\section{Results}

The relationship between caring roles and employment participation

Table 5 shows how the change in employment status between ages $5^{\mathrm{O}}$ and 55 varies by our three caring variables as well as by the wider socio-economic characteristics of the sample. Looking first at the three care-giving predictors, there is a significant bivariate association between carers' employment patterns and the types of care-giving and the intensification of caring. However, no association was found with the care-giving trajectories. The impact of caregiving on the carer's employment appears to be strongest amongst men carers who are providing basic care and women carers providing personal care, and amongst both men and women carers who increased their caring hours between the two waves. These findings highlight the challenge faced by carers in combining more intense care provision over time with employment. The key question is whether these differences remain after controlling for other characteristics.

In terms of the wider socio-economic characteristics of the sample (also in Table 5) the majority of respondents were married or in a partnership at baseline, and only a relatively low proportion were co-resident with their parents (around 4\%). Most of the respondents described their health as good, very good or excellent. More than two-thirds had achieved high O-level qualifications (i.e. five or more grade $\mathrm{A}-\mathrm{C}$, equivalent to high school diploma) or higher levels of education. About one-third of the 
T A B L E 5. Characteristics of the individuals at risk of caring by sex and employment changes between ages 50 and 55

\begin{tabular}{|c|c|c|c|c|c|c|c|c|c|c|}
\hline & \multicolumn{10}{|c|}{ Employment change between ages $5^{\circ}$ and 55} \\
\hline & $\begin{array}{l}\text { Did not } \\
\text { reduce } \\
\text { hours }\end{array}$ & $\begin{array}{l}\text { Reduced } \\
\text { hours }\end{array}$ & $\begin{array}{l}\text { Stopped } \\
\text { working }\end{array}$ & Total & $\mathrm{N}$ & $\begin{array}{l}\text { Did not } \\
\text { reduce } \\
\text { hours }\end{array}$ & $\begin{array}{l}\text { Reduced } \\
\text { hours }\end{array}$ & $\begin{array}{l}\text { Stopped } \\
\text { working }\end{array}$ & Total & $\mathrm{N}$ \\
\hline & \multicolumn{4}{|c|}{ Percentages } & \multicolumn{6}{|c|}{ Percentages } \\
\hline Types of care-giving (age 55): & & & & & & & & & & \\
\hline Instrumental care only & $5^{0.4}$ & 42.9 & 6.7 & 100.0 & 1,328 & $49 \cdot 7$ & $4^{1.0}$ & $9 \cdot 3$ & 100.0 & 867 \\
\hline \multicolumn{11}{|l|}{ Care-giving trajectories: } \\
\hline New carers & $4^{8.7}$ & $4^{2.8}$ & 8.5 & 100.0 & 542 & $4^{8.5}$ & 41.9 & $9 \cdot 7$ & 100.0 & $4^{66}$ \\
\hline Repeated caring & 48.7 & $44 \cdot 3$ & 7.0 & 100.0 & 1,502 & 47.2 & 41.5 & 11.3 & 100.0 & 1,209 \\
\hline Stopped caring & $4^{8.2}$ & $44 \cdot 4$ & $7 \cdot 4$ & 100.0 & $33^{6}$ & $47 \cdot 3$ & 41.6 & 11.1 & 100.0 & 279 \\
\hline Non-carer & $47 \cdot 4$ & $43 \cdot 6$ & 9.0 & 100.0 & 633 & $5^{0.5}$ & $4^{0.2}$ & $9 \cdot 3$ & 100.0 & 654 \\
\hline $\begin{array}{l}\text { Increased hours (change of }>5 \\
\text { hours between ages } 5^{\mathrm{O}} \text { and } 55 \text { ) }\end{array}$ & 47.6 & $3^{8.7}$ & $13 \cdot 7$ & 100.0 & 212 & 43.2 & $4^{0.2}$ & 16.6 & 100.0 & 229 \\
\hline \multicolumn{11}{|l|}{ Self-perceived health: } \\
\hline Excellent & $5^{0.3}$ & $44 \cdot 1$ & $5.6 * *$ & 100.0 & 666 & $4^{8.2}$ & $4^{2.5}$ & $9 \cdot 3^{* *}$ & 100.0 & 614 \\
\hline Very good & $49 \cdot 3$ & 43.0 & $7 \cdot 7$ & 100.0 & 1,102 & $5^{0.0}$ & 41.1 & 9.0 & 100.0 & 967 \\
\hline Good & 47.6 & $45 \cdot 1$ & $7 \cdot 3$ & 100.0 & 905 & $4^{8.1}$ & 41.4 & 10.4 & 100.0 & 748 \\
\hline Fair/poor & 43.8 & 42.9 & 13.2 & 100.0 & $34^{\circ}$ & $43 \cdot 0$ & 38.7 & 18.3 & 100.0 & 279 \\
\hline
\end{tabular}




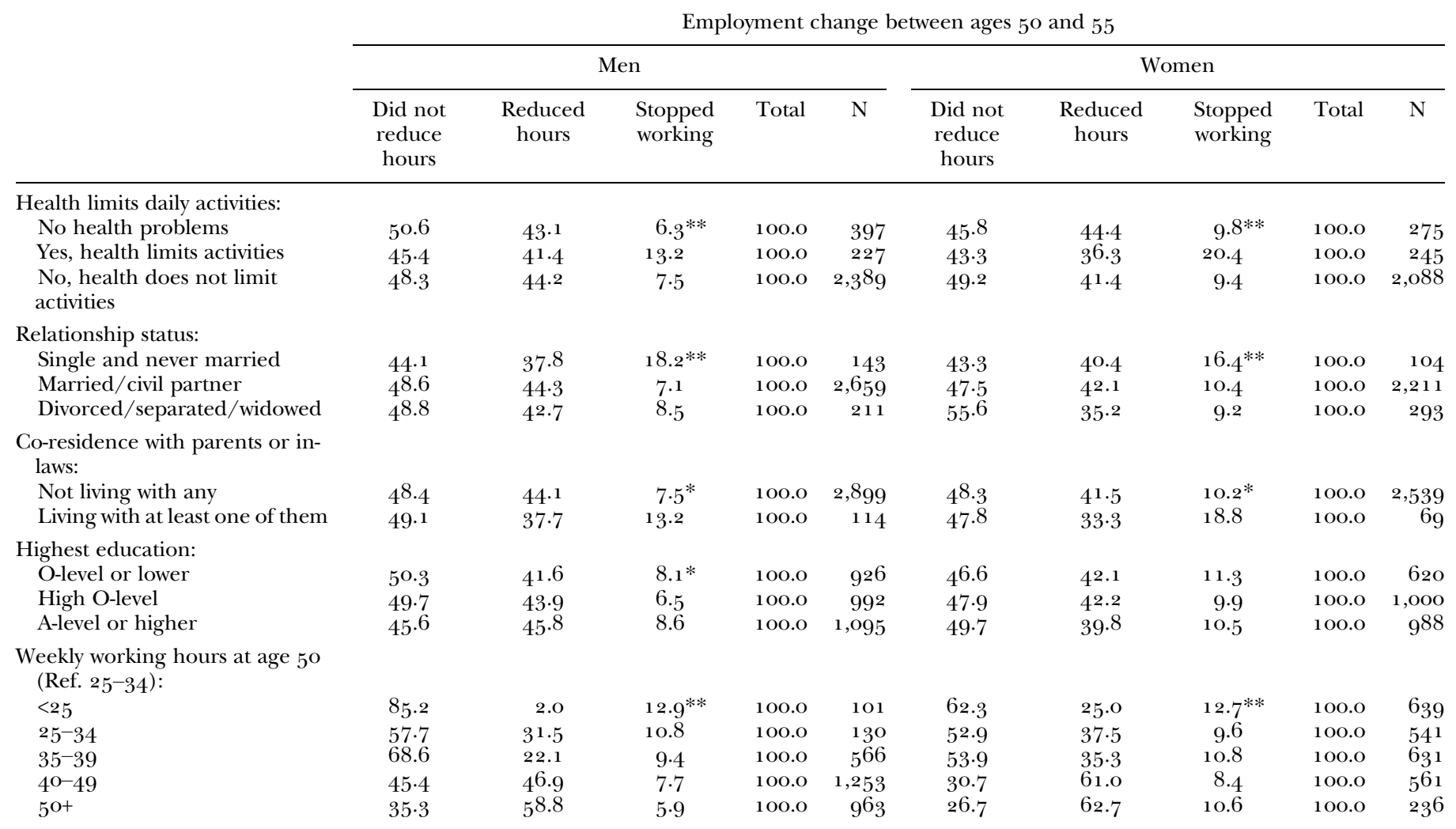


Occupational category:

Higher managerial

Lower managerial and profes-

sional occupations

Small employers, own-account

workers and lower supervisor

occupations

Semi-routine and routine

occupations

Economic status of the partner:

$$
\text { No partner }
$$

Full-time job (3o+ hours)

Part-time job (<30 hours)

Not working

\begin{tabular}{|c|c|c|c|c|c|c|c|c|c|}
\hline 47.6 & $44 \cdot 6$ & $7.8^{*}$ & 100.0 & 639 & $4^{2.0}$ & $4^{6.7}$ & $11.4^{* *}$ & 100.0 & 255 \\
\hline $45 \cdot 3$ & $4^{6.3}$ & 8.4 & 100.0 & 1,063 & $4^{8.7}$ & $4^{1.6}$ & $9 \cdot 7$ & 100.0 & 1469 \\
\hline $5^{0.8}$ & $4^{2.7}$ & 6.5 & 100.0 & 899 & $45 \cdot 7$ & $45 \cdot 7$ & 8.6 & 100.0 & 302 \\
\hline $5^{2.2}$ & $39 \cdot 1$ & 8.7 & 100.0 & 412 & $5^{1.2}$ & $35 \cdot 7$ & 13.1 & 100.0 & $5^{82}$ \\
\hline $4^{6.9}$ & $4^{0.7}$ & $12.4^{* *}$ & 100.0 & 354 & $5^{2 \cdot 4}$ & 36.5 & 11.1 & 100.0 & 397 \\
\hline $47 \cdot 7$ & $45 \cdot 5$ & 6.8 & 100.0 & 1,281 & 47.8 & $4^{2.1}$ & 10.1 & 100.0 & 1,899 \\
\hline $4^{8.9}$ & $45^{\circ} \mathrm{O}$ & 6.1 & 100.0 & 926 & 37.8 & 49.6 & 12.6 & 100.0 & 111 \\
\hline $5^{0.4}$ & $39 \cdot 4$ & 10.2 & 100.0 & $45^{2}$ & $5^{0.3}$ & 37.8 & 11.9 & 100.0 & 201 \\
\hline $4^{6.4}$ & $45 \cdot 6$ & $8.1^{* *}$ & 100.0 & 643 & 47.1 & $4^{1.2}$ & $11.7^{* *}$ & 100.0 & 692 \\
\hline $49 \cdot 7$ & $43 \cdot 4$ & 7.0 & 100.0 & 2,076 & $49 \cdot 5$ & $4^{1.2}$ & $9 \cdot 3$ & 100.0 & 1,670 \\
\hline $43 \cdot 9$ & $43 \cdot 9$ & 12.2 & 100.0 & 294 & 43.1 & $4^{1} \cdot 9$ & 15.0 & 100.0 & 246 \\
\hline
\end{tabular}

Housing tenure:

Own outright

Own with mortgage

43.9

100.0 $294 \quad 43.1$

$41 \cdot 9$

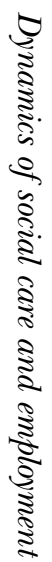

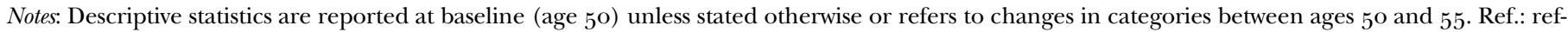
erence category.

Significance levels: $* p<0.05, * * p<0.01$. 
T А в L E 6 . Logistic regression models for 'exit from work' and among those who continue working 'reduced work hours', by care-giving roles among men

\begin{tabular}{|c|c|c|c|c|c|c|c|c|c|c|c|c|}
\hline \multirow[b]{3}{*}{ Predictors } & \multicolumn{6}{|c|}{ Exit work } & \multicolumn{6}{|c|}{ Reduced work hours } \\
\hline & \multicolumn{2}{|c|}{ Model 1} & \multicolumn{2}{|c|}{ Model 2} & \multicolumn{2}{|r|}{ Model 3} & \multicolumn{2}{|c|}{ Model 4} & \multicolumn{2}{|c|}{ Model 5} & \multicolumn{2}{|c|}{ Model 6} \\
\hline & OR & $95 \% \mathrm{CI}$ & OR & $95 \% \mathrm{CI}$ & OR & $95 \% \mathrm{CI}$ & OR & $95 \% \mathrm{CI}$ & OR & $95 \% \mathrm{CI}$ & OR & $95 \%$ CI \\
\hline \multicolumn{13}{|c|}{ Types of care-giving (Ref. Did not provide care): } \\
\hline Personal care combined & 1.06 & $0.57,1.98$ & & & & & 0.67 & $0.4^{6}, 0.97^{* *}$ & & & & \\
\hline Basic care combined & 1.14 & $0.77,1.69$ & & & & & 1.16 & $0.91,1.4^{6}$ & & & & \\
\hline Instrumental care only & 0.84 & $0.61,1.16$ & & & & & 0.88 & $0.73,1.07$ & & & & \\
\hline \multicolumn{13}{|c|}{ Caring trajectories (Ref. Non-carer): } \\
\hline New carers & & & 1.03 & $0.68,1.57$ & & & & & 0.94 & $0.73,1.21$ & & \\
\hline Repeated caring & & & 0.81 & $0.57,1.16$ & & & & & 0.96 & $0.78,1.18$ & & \\
\hline Stopped caring & & & 0.82 & $0.5^{0}, 1.3^{6}$ & & & & & 1.08 & $0.80,1.4^{6}$ & & \\
\hline \multicolumn{13}{|c|}{ Intensification of caring (Ref. Non-carer): } \\
\hline Stopped caring & & & & & $0.8_{3}$ & $0.5^{\circ}, 1.37$ & & & & & 1.08 & $0.80,1.4^{6}$ \\
\hline $\begin{array}{l}\text { New carer or carers with } \\
\text { same/reduced hours }\end{array}$ & & & & & 0.79 & $0.57,1.12$ & & & & & 0.97 & $0.79,1.18$ \\
\hline $\begin{array}{l}\text { Increased hours (increase } \\
\text { of }>5 \text { hours / week between } \\
\text { ages } 5^{\circ} \text { and } 55 \text { ) }\end{array}$ & & & & & 1.65 & $0.99,2.72^{*}$ & & & & & 0.84 & $0.5^{6,1.20}$ \\
\hline Individuals & & 3,013 & & 3,013 & & 3,013 & & 2,780 & & 2,780 & & 2,780 \\
\hline
\end{tabular}

Notes: Ref.: reference category. OR: odds ratio. CI: confidence interval. Adjusted for health perceived, health limiting daily activities, co-residence with parents/parents-in-law, working hours, occupation, partner's employment status, education and housing tenure (results for the covariates can be found in the online supplementary material).

Significance levels: $* p<0.05, * * p<0.01$. 
respondents were working in lower managerial and professional occupations, followed by small employers, own-account workers and lower supervisor occupations, and working in semi-routine and routine occupations.

Looking at changes in employment status, respondents with health limitations or reporting fair/poor self-perceived health were more likely to stop working. Stopping work was also associated with being single/never married, co-residing with one's parents or parents-in-law, working in lower occupational categories, and living in rented accommodation or other arrangements.

Two sets of logistic regressions are used to test the effect of the three caregiving predictors (tested independently) on changes in employment, controlling for socio-demographic and health characteristics. For the first set of three models, the outcome variable is exit work, whereas the second set of models are conditional on the respondents being in employment at both ages in order to measure changes in their working hours, with the outcome variable being reduced work hours.

Tables 6 and 7 show the results of the logistic regressions for both exiting employment and reducing working hours for men and women, respectively (the results for the covariates in the models are presented in Tables $\mathrm{S}_{1}$ and $\mathrm{S}_{2}$ in the online supplementary material). Interestingly, the second predictor that distinguishes the caring trajectories was not significant in any of the employment outcome variables, for either men or women (Models 2 and 5 in Tables 6 and 7). If the analysis was limited to this variable alone, the results could suggest that at this stage of the care-giver's life, taking on a new caring role or repeating such a role is not affecting their employment participation. However, this might be misleading as when the type of care provided and, especially, the intensification of the caring role are considered, there appears to be a significant impact on employment.

Interestingly, those men who provided personal care were less likely to reduce their working hours than those who did not provide any care at all (Table 6, Model 4), such men remain however a minority group, with just 5 per cent of men providing personal care at age 55 . For women, those providing personal care were 1.79 times more likely to stop working than those not providing care (Table 7 , Model 1). For the third predictor, as we expected, an increase in the hours of caring had a negative effect on the employment status of both men and women. Men who increased their caring hours were 1.65 times more likely to stop working, whereas such an increase almost doubled the risk of leaving employment among women (odds ratio $=1.97$ ). Interestingly, however, amongst those who remained in work at age 55 , there were no significant differences in the odds of reducing working hours amongst those who increased their caring commitment compared with those who 'never' cared, for both men and women. 
Tests for interaction effects with the covariates showed that for the models of stopping work there is a significant association with self-reported health. Worse self-reported health is associated with a lower risk of stopping work among women repeat carers compared to non-carers (Figure 1a). A similarly low risk was found for both men and women providing instrumental care compared with non-carers.

For the models of reducing carer's working hours, the partners' employment status becomes significant (Figure $1 \mathrm{~b}$ ). Women without a partner in any of the care-giving roles are more likely to reduce their working hours than non-carers, however, those with partners who work full-time are less likely to reduce their working hours. Significant interactions are observed for the caring trajectories and types of help provided by male carers, although this is not the case for the intensification of the care. Men with partners working full-time who stopped caring were more likely to reduce their working hours compared with non-carers. However, for those with no partners the opposite effect is found, as they were less likely to reduce their hours of work.

\section{Discussion}

This research has focused on the impact of care-giving responsibilities towards parents/parents-in-law on the employment status of adult children in mid-life. Using recent cohort data from the NCDS, the paper investigated the impact of caring on employment between the ages of $5^{\mathrm{O}}$ and 55 , controlling for a wide range of socio-demographic and health characteristics of the care-giver and their partner. The findings lend partial support to both the time conflict and role enhancement hypotheses. Firstly, it was found that those who have provided support which has been increasing over time, as well as women providing (more demanding) personal support, were more likely to stop working. Such effects were stronger for women than for men, lending support to the conflict hypothesis and confirming existing research (Berecki-Gisolf et al. 2008; Carmichael and Charles 2003; Ciani 2012). However, unlike previous studies analysing general trends of care provision and employment participation (Heitmueller 2007; Michaud, Heitmueller and Nazarov 2010), this study did not find an association between the adult children's employment and other family characteristics such as living with dependent children, or the carer's income and level of education.

Secondly, contrary to previous studies which focused on both genders (Carr et al. 2016; Van Houtven, Coe and Skira 2013), adjusting one's working hours was found to be statistically significant only for men. Men providing personal care were less likely to reduce their working hours 


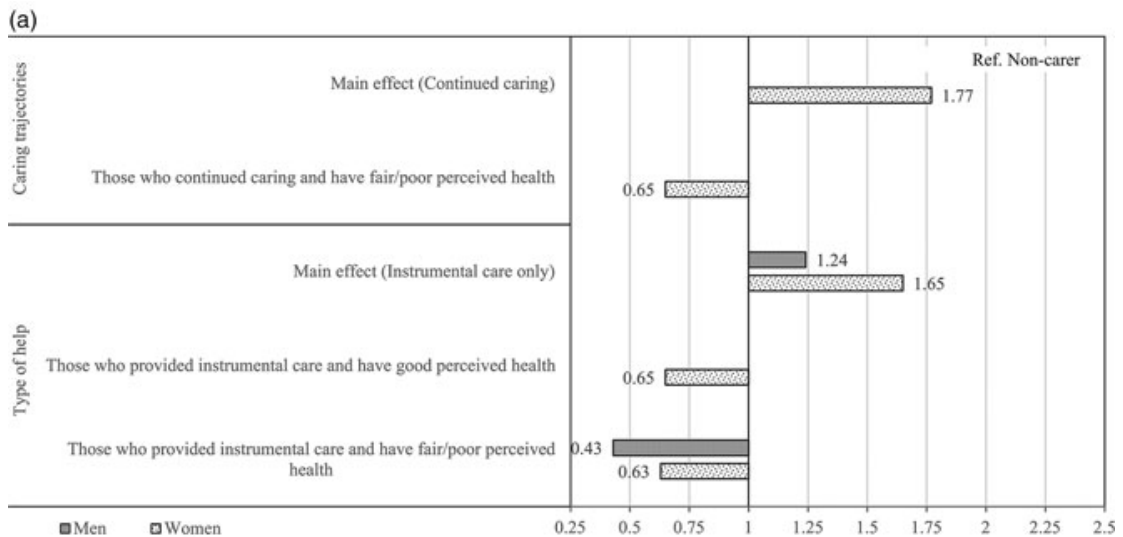

(b)

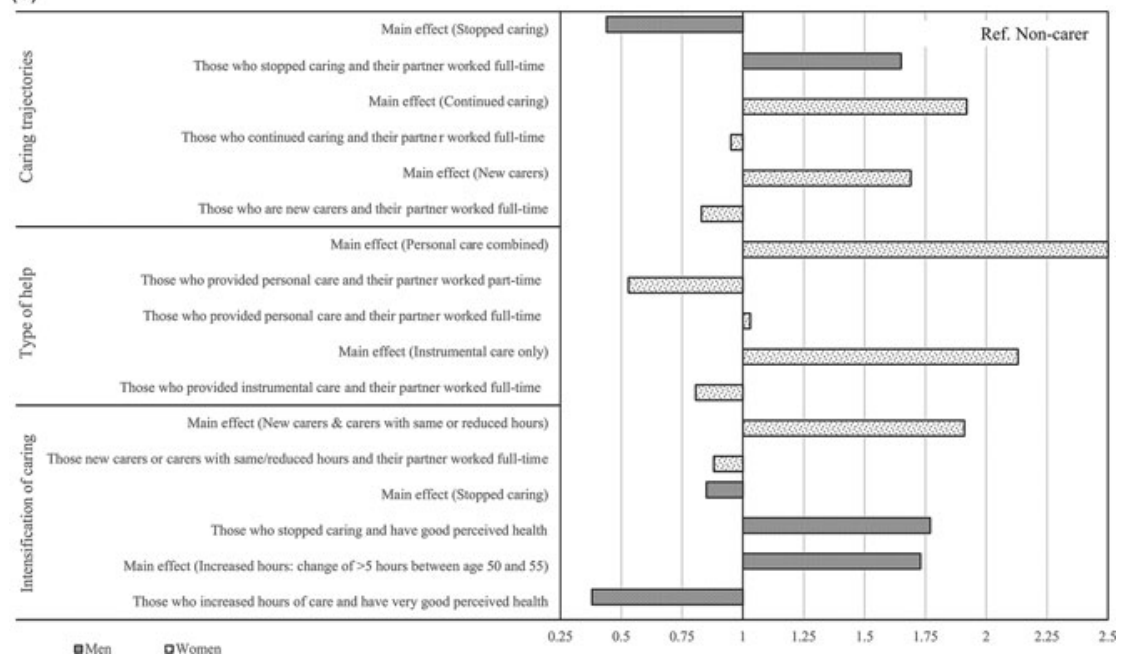

Figure 1. Results for the interaction effects of the logistic regression models for (a) 'exit from work' and (b) among those who continue working 'reduced work hours', by care-giving roles among men and women (main effects and significant interaction effects).

Note: Ref.: reference category.

than those who did not provide any care, which lends support to the role enhancement hypothesis. This finding could indicate a need to continue with the same amount of working hours due to financial issues, as a respite from caring duties, or in combination with care provision by other care-givers, such as the spouse/partner. Further analysis is needed in order to explore such assumptions.

The analysis showed that a significant proportion of both men and women caring for parents/parents-in-law change their employment 
patterns in order to accommodate their caring role. Particularly interesting is that with a wider range of care types and a measure of intensification of the caring role, the impact of caring on employment differs for men and women. Exiting employment altogether is a risk affecting both men and women carers, while reducing one's working hours appears to be a risk only affecting men. This may point to a scenario where women are faced with an "either or" choice of continuing to work or not, or pointing to the fact that they have already changed their working patterns long before reaching mid-life.

Comparisons with previous studies are difficult given the inconsistency of measures of care-giving used in each one. However, some similarities and differences can be highlighted. Previous studies have found a negative impact of intense care on employment, using a threshold of 20 or $5^{0}$ hours or more per week of care provision (Heitmueller 2007; Robards et al. 2015 ; Trukeschitz et al. 2013; Vlachantoni 2010). Others have found that even provision of care at the lower threshold of ten hours or more per week negatively affects the carer's employment (King and Pickard 2013; Van Houtven, Coe and Skira 2013). Our study suggests that we should also take into account the changes in the intensity of care provision over time, not only whether the caring role is starting or repeating, as well as the intensity of the care provided at one point in time. We did not find any effect of the caring trajectory on carer's employment, however, we did find a negative effect of increasing hours of caring provided over time for both men and women. Interestingly, a relatively low threshold of increasing one's care by five hours or more per week was shown as sufficient to affect the employment participation of the care-givers (the threshold of ten hours showed similar results). This finding may indicate ineffective support or flexibility on the part of employers in the UK, which has been evidenced in previous research (Carmichael et al. 2008), or it could reflect a threshold at which the carers decide to withdraw from the labour market in order to focus on their caring role. The latter possibility would require in-depth qualitative research with carers in order to be explored.

Previous research has found that the type of care is a significant factor affecting changes in employment practices, with more intense or more demanding types of care having a more negative effect (Heitmueller 2007; Van Houtven, Coe and Skira 2013). Our key contribution to this debate is that the type of care and the intensification of the caring role should both be taken into account when exploring this relationship among both men and women carers, as the effects are different for each sex. While for women, more demanding types of care affect their chances of remaining in employment per se, men's employment is more likely to be affected in terms of a reduction in the number of working hours. 
Moreover, the carer's health and their partner's employment status both seem to play a moderating role between caring and employment, which should also be taken into account.

There are certain methodological limitations that need to be borne in mind when interpreting these results. Firstly, the caring trajectories variable and the intensification of caring variable were constructed using information collected at ages $5^{\mathrm{O}}$ and 55 . However, these variables may include respondents who stopped providing care for a period of time between the two points, or who were providing care to a different parent/parent-in-law at each point. Thus, although we are assuming that repeated spells of caring reflect a continuation or an extended duration in one's caring role, in reality these patterns may be more complex. Secondly, the results could be affected by unobserved heterogeneity due to the lack of information on specific aspects of the care activity. For instance, the data-set did not include information on the health of the parents/parents-in-law, which may affect the demand for care; neither could information regarding the receipt of formal care or informal care from other sources be included, which could also influence the adult children's involvement in the provision of care (Michaud, Heitmueller and Nazarov 2010 ; Sole-Auro and Crimmins 2014). Such variables are included in other nationally representative datasets such as the English Longitudinal Study of Ageing, which are less appropriate than the NCDS for cohort-specific analysis. Thirdly, this paper has utilised data when the respondents were $5^{\mathrm{O}}$ and 55 years old, however, the examination of the impact of caring on employment may present even stronger effects if future waves of the NCDS are utilised (e.g. when the respondents are aged 60 years or more), albeit with a higher risk of attrition as a result of older parents'/parents'-in-law mortality. A fourth limitation is that we are unable to explicitly take into account the temporal ordering of events, and therefore we cannot fully assess the causal effect of caring on employment. Finally, the care recipients in this paper are concentrated among parents/parents-in-law only which, on the one hand, allows us to explore care provision towards individuals outside the spousal relationship and in the wider family network, but on the other hand, precludes the examination of other types of care recipients which may place increasing demands for care over time on individuals in mid-life.

These results have important implications for government policies. On the one hand, in order to meet the goals of the European Union relating to the increasing participation rates amongst older workers set in the Lisbon Agenda (http://ec.europa.eu/growthandjobs/index.htm) and among men and women of working age (Europe 2020) (European Commission 2010), many governments are now introducing policies to extend working lives, including in the UK raising the state pension age. However, in order 
to meet the growing care needs of the ageing population, an increasing number of mid-life adult children will need to provide care, and supporting these adult children to reconcile employment and care-giving successfully will be a precondition to securing future family care-giving. There are strong economic incentives to do so. If carers are not able to combine their caring responsibilities with work, there are implications for government, with a reduction in revenues due to a reduction in income tax; for business, with a loss of skilled workers; and for individuals, who may face financial constraints due to the loss or reduction of wages whilst caring and also lower pension entitlements in later life (Evandrou and Glaser 2003). It is estimated that the cost of providing elder-care in terms of lost productivity to US businesses is over US $\$ 17$ billion a year (MetLife Mature Market Institute and National Alliance for Caregiving 20o6), whilst the annual costs of not reconciling employment and elder-care have been estimated in Germany at $€_{14}$,200 per employee (Schneider, Heinze and Hering 2011).

Our research highlights the importance of flexibility in employment in supporting carers to remain in work, with those carers whose partners are in part-time employment being less likely to reduce their work hours or stop work altogether. However, it also suggests that much more remains to be done to support those adult children who are experiencing an intensification of their caring roles. Many of these are women, reflecting the gendered nature of caring roles. However, interestingly our research suggests that men also tend to reduce their working hours or stop working when they are involved in intense care-giving or particular types of care. This is not necessarily a positive; previous research has shown that women may be trapped in low-paid part-time jobs in order to combine paid work with care-giving (Buckner and Yeandle 2006). Research also suggests that men may feel less able to approach their line managers and that women are more likely to request flexible working arrangements than men such as flexi-time or working from home (Tipping et al. 2012). Since June 2014, within the $\mathrm{UK}$, the right to request flexible working has been extended to cover all employees with 26 weeks of service, regardless of the number of hours of care provided. This is a welcome step in the right direction; how this will impact upon the relationship between social care and employment in mid-life remains to be assessed.

\section{Supplementary material}

To view supplementary material for this article, please visit https://doi.org/ $10.1017 /$ So $144686 X_{17000964}$ 


\section{Acknowledgements}

This research is part of the Economic and Social Research Council Centre for Population Change (grant number ES/Koo7394/1) at the University of Southampton.

\section{References}

Agree, E. and Glaser, K. 20og. Demography of informal caregiving. In Uhlenberg, P. (ed.), International Handbook of Population Aging. Volume 1, Springer, Dordrecht, The Netherlands, $647-68$.

Berecki-Gisolf, J., Lucke, J., Hockey, R. and Dobson, A. 2008. Transitions into infor-

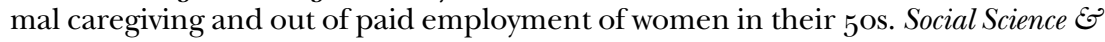
Medicine, 67, 1, 122-7.

Buckner, L. and Yeandle, S. 20o6. Statistical Analysis - Working Carers: Evidence from the 200 I Census. Carers UK, London.

Carmichael, F. and Charles, S. 2003. The opportunity costs of informal care: does gender matter? Journal of Health Economics, 22, 5, 781-803.

Carmichael, F., Charles, S. and Hulme, C. 2010 . Who will care? Employment participation and willingness to supply informal care. Journal of Health Economics, 29, 1, $182-90$.

Carmichael, F., Hulme, C., Sheppard, S. and Connell, G. 20o8. Work-life imbalance: informal care and paid employment in the UK. Feminist Economics, 14, 2, 3-35.

Carr, E., Murray, E. T., Zaninotto, P., Cadar, D., Head, J., Stansfeld, S. and Stafford, M. 2016. The association between informal caregiving and exit from employment among older workers: prospective findings from the UK Household Longitudinal Study. Journals of Gerontology: Psychological Sciences and Social Sciences. Published online December 6, 2016. doi:10.1093/geronb/ gbw1 56 [Accessed 31 March 2017].

Christensen, K., Doblhammer, G., Rau, R. and Vaupel, J. 20o9. Ageing populations: the challenges ahead. The Lancet, 374, 9696, $1196-208$.

Ciani, E. 2012. Informal adult care and caregivers' employment in Europe. Labour Economics, 19, 2, $155^{-64}$.

European Commission 2010. Europe 2020: A Strategy for Smart, Sustainable and Inclusive Growth. European Commission, Brussels.

Evandrou, M. and Glaser, K. 2003. Combining work and family life: the pension penalty of caring. Ageing $\mathcal{E}^{2}$ Society, 23, 5, 583-6o1.

Evandrou, M., Glaser, K. and Henz, U. 2002. Multiple role occupancy in midlife: balancing work and family life in Britain. Gerontologist, 42, 6, 781-9.

Farkas, J. I. and Himes, C. L. 1997. The influence of caregiving and employment on the voluntary activities of midlife and older women. Journals of Gerontology: Psychological Sciences and Social Sciences, 52B, 4, S180-9.

Glaser, K., Evandrou, M. and Tomassini, C. 2006. Multiple role occupancy and social participation among midlife wives and husbands in the United Kingdom. International Journal of Aging and Human Development, 63, 1, 27-47.

Goode, W.J. 1960. A theory of role strain. American Sociological Review, 25, 4, 483-96.

Greenhaus, J. H., Collins, K. M. and Shaw, J. D. 2003. The relation between workfamily balance and quality of life. Journal of Vocational Behavior, 63, 3, $5^{10-31}$. 
Grzywacz, J. G. and Marks, N. F. 2000. Reconceptualizing the work-family interface: an ecological perspective on the correlates of positive and negative spillover between work and family. Journal of Occupational Health Psychology, 5, 1, 111 1-26.

Hawkes, D. and Plewis, I. 20o6. Modelling non-response in the National Child Development Study. Journal of the Royal Statistical Society: Series A (Statistics in Society), 169, 3, 479-91.

Heitmueller, A. 2007. The chicken or the egg? Endogeneity in labour market participation of informal carers in England. Journal of Health Economics, 26, 3, 536-59.

King, D. and Pickard, L. 2013. When is a carer's employment at risk? Longitudinal analysis of unpaid care and employment in midlife in England. Health $\mathcal{E}^{\circ}$ Social Care in the Community, $\mathbf{2 1}, 3,3^{\circ}-14$.

Lee, Y. and Tang, F. 2015. More caregiving, less working: caregiving roles and gender difference. Journal of Applied Gerontology, 34, 4, 465-83.

Lee, Y., Tang, F., Kim, K. H. and Albert, S. M. 2014. The vicious cycle of parental caregiving and financial well-being: a longitudinal study of women. Journals of Gerontology: Psychological Sciences and Social Sciences, 7oB, 3, 425-31.

Leigh, A. 2010. Informal care and labor market participation. Labour Economics, 17, $1,140-9$.

Lilly, M. B., Laporte, A. and Coyte, P. C. 2010. Do they care too much to work? The influence of caregiving intensity on the labour force participation of unpaid caregivers in Canada. Journal of Health Economics, 29, 6, 895-9o3.

Litwin, H. and Stoeckel, K. J. 2013. The social networks of older Europeans. In Phellas, C. (ed.), Aging in European Societies. Springer, New York, 177-9o.

Loken, K. V., Lundberg, S. and Riise, J. 2014. Lifting the burden: state care of the elderly and labor supply of adult children. Working Papers in Economics, 3, 14, 1-44.

Lumsdaine, R. and Vermeer, S. C. 2015 . Retirement timing of women and the role of care responsibilities for grandchildren. Demography, 52, 2, 433-54.

Marks, S. R. 1977. Multiple roles and role strain: some notes on human energy, time and commitment. American Sociological Review, 42, 6, $921-36$.

MetLife Mature Market Institute and National Alliance for Caregiving 20o6. The MetLife Caregiving Cost Study: Productivity Losses to U.S. Business. Metropolitan Life Insurance Company, New York.

Michaud, P.-C., Heitmueller, A. and Nazarov, Z. 2010 . A dynamic analysis of informal care and employment in England. Labour Economics, 17, 3, 455 $5_{5}$.

Plaisier, I., Broese van Groenou, M. I. and Keuzenkamp, S. 2015 . Combining work and informal care: the importance of caring organisations. Human Resource Management Journal, 25, 2, 267-80.

Proulx, C. and Le Bourdais, C. 2014. Impact of providing care on the risk of leaving employment in Canada. Canadian Journal on Aging, 33, 4, 488-503.

Robards, J., Vlachantoni, A., Evandrou, M. and Falkingham, J. 2015. Informal caring in England and Wales - stability and transition between 2001 and 2011 . Advances in Life Course Research, 24, 21-33.

Schneider, H., Heinze, J. and Hering, D. 2011. Betriebliche Folgekosten Mangelnder Vereinbarkeit von Beruf und Pflege [Company-based Follow-up Costs of Lacking Reconciliation of Employment and Elder-care]. Steinbeis University, Berlin.

Skira, M. M. 2015. Dynamic wage and employment effects of elder parent care. International Economic Review, 56, 1, 63-93.

Sole-Auro, A. and Crimmins, E. M. 2014. Who cares? A comparison of informal and formal care provision in Spain, England and the USA. Ageing $\mathcal{E}$ Society, 34, $3,495^{-} 5^{17}$. 
Stewart, L. M. 2013. Family care responsibilities and employment: exploring the impact of type of family care on work-family and family-work conflict. Journal of Family Issues, 34, 1, $113-38$.

Tipping, S., Chantreau, J., Perry, J. and Tait, C. 2012. The Fourth Work-Life Balance Employee Survey. National Centre for Social Research, London.

Trukeschitz, B., Schneider, U., Mühlmann, R. and Ponocny, I. 2013. Informal eldercare and work-related strain. Journals of Gerontology: Psychological Sciences and Social Sciences, 68B, 2, 257-67.

University of London, Institute of Education and Centre for Longitudinal Studies 2012. National Child Development Study: Sweep 8, 2008-2009 [data collection]. Third edition, UK Data Service. SN: 6137, http://dx.doi.org/10.5255/UKDASN-6137-2.

University of London, Institute of Education and Centre for Longitudinal Studies 2015. National Child Development Study Response and Outcomes Dataset, 1958-2013 [data collection]. $5^{\text {th }}$ edition, UK Data Service. SN: $55^{60}$, http://doi.org/10. $5^{2} 55^{\text {/UKDA-SN- } 55^{60}-3 \text {. }}$

Van Houtven, C. H., Coe, N. B. and Skira, M. M. 2013. The effect of informal care on work and wages. Journal of Health Economics, 32, 1, 240-52.

Vlachantoni, A. 2010. The demographic characteristics and economic activity patterns of carers over $5^{\mathrm{o}}$ : evidence from the English Longitudinal Study of Ageing. Population Trends, 141, 1, 51-73.

Vlachantoni, A., Shaw, R., Evandrou, M. and Falkingham, J. 2015. The determinants of receiving social care in later life in England. Ageing $\mathcal{E}$ Society, 35, 2, $321-45$.

Wittenberg, R., Comas-Herrera, A., King, D., Malley, J., Pickard, L. and Darton, R. 2006. Future demand for long-term care, 2002 to 2041: projections of demand for long-term care for older people in England. Discussion Paper 2330. PSSRU: London School of Economics, London.

Accepted 8 August 2017 ; first published online 20 September 2017

Address for correspondence.

Athina Vlachantoni,

Centre for Research on Ageing and ESRC Centre for Population Change,

Faculty of Social, Human and Mathematical Sciences,

University of Southampton,

Southampton $\mathrm{SO}_{1} 7 \mathrm{BJ}$, UK

E-mail: a.vlachantoni@soton.ac.uk 